\title{
Suicide: an existentialist reconceptualization
}

M. Roberts and E. Lamont

This is the accepted version of the following article:

Roberts, M. and Lamont, E. 2014. Suicide: an existentialist reconceptualization. Journal of Psychiatric and Mental Health Nursing. 21(10): pp.873-878. doi: 10.1111/jpm.12155

which has been published in final form at http://dx.doi.org/10.1111/ jpm.12155. This article may be used for non-commercial purposes in accordance with Wiley Terms and Conditions for Self-Archiving. 


\title{
Suicide: an existentialist reconceptualization
}

\author{
Authors \\ M. Roberts and E. Lamont, \\ Division of Nursing \& Counselling, University of Abertay, Dundee, UK
}

\begin{abstract}
The phenomenon of suicide is one of the primary concerns for mental health professions. The health care literature is dominated by discussions that focus variously on local and national suicide prevention policies, on the assessment of those individuals judged to be at risk of committing suicide as well as the appropriateness and efficacy of interventions for those who express suicidal ideation and display suicidal behaviours. What appear less frequently in the literature, however, are critical analyses of the concept of suicide and, in particular, critical reflections on the manner in which the concept of suicide has been, and continues to be, understood or 'framed'. In an attempt to respond to this apparent omission, this paper will suggest that the work of Albert Camus, and his philosophical work The Myth of Sisyphus in particular, can be understood as providing a significant reconceptualization and reframing of suicide. In doing so, it will be suggested that Camus's work not only challenges how the concept of suicide has traditionally been situated within the context of mental illness, but can also be understood as challenging the efficacy of the interventions that have been associated with an understanding of suicide within that context.
\end{abstract}




\section{Accessible summary}

- The twentieth century intellectual Albert Camus, and specifically his philosophical essay The Myth of Sisyphus, can be understood as providing a significant perspective on suicide.

- In particular, Camus situates the phenomena of suicide within the context of the uniquely human endeavour to make sense of the struggles and sorrows of life.

- In doing so, his work challenges both the manner in which suicide has been understood within the context of mental illness, and the custodial and defensive practices that are associated with such an understanding of suicide. 


\section{Introduction}

Albert Camus, the French-Algerian playwright, novelist and writer of philosophical essays, is generally acknowledged as being one of the most important cultural and intellectual figures of the twentieth century (see, e.g. Bronner 1999, Hughes 2007, Zaretsky 2013). While he explicitly sets himself against 'existentialist philosophies' (Camus 2000a, p. 35), Camus is commonly understood as belonging to the existentialist tradition of Continental philosophy (West 2010, pp. 169-170), and of having explored a variety of existentialist themes in his literary and philosophical works (see, e.g. 2000a, 2000b, 2000c, 2000d, 2000e) that retain a significance for contemporary men and women. Indeed, in highlighting the enduring significance of Camus's work and the themes that he explored within that work, Zaretsky (2010) has suggested that: 'If there is one conviction that scholars and nonscholars share, it is that Camus is still an indispensable companion in our intellectual and ethical lives. $\mathrm{He}$ appears to us, in a way that few other writers do, as someone who wrote for his life and for our lives as well' (p. 2). This paper will propose that Camus's work can also be understood as possessing an enduring, contemporary significance for the theoretical concerns and therapeutic practices of the mental health profession and that his work can be employed to formulate a significant reconceptualization of the phenomenon of suicide. In doing so, the paper will focus exclusively on his philosophical essay The Myth of Sisyphus (in so far as it is here that he conducts his most systematic discussion of suicide) to suggest that Camus provides an existentialist reconceptualization of suicide. In particular, it will be suggested that he not only challenges the manner in which suicide has traditionally been understood or 'framed' within the context of mental illness, but also challenges the appropriateness of the interventions that have been associated with understanding suicide within that context. 


\section{Suicide and mental illness}

The phenomenon of suicide is one of the primary concerns for mental health professions. The health care literature is dominated by discussions that focus variously on local and national suicide prevention policies, on the assessment of those individuals judged to be at risk of committing suicide as well as the appropriateness and efficacy of interventions for those who express suicidal ideation and display suicidal behaviours (see, e.g. Hawton 2005, O’Connor et al. 2011, Cutcliffe \& Santos 2012). What appear less frequently in the literature, however, are critical analyses of the concept of suicide and, in particular, critical reflections on the manner in which the concept of suicide has been, and continues to be, framed. That is, the concept of suicide - as with all concepts (Deleuze \& Guattari 2003, pp. 5-8) - is not to be understood as an ahistorical or unproblematic category. Rather, the concept of suicide is to be understood as possessing a rich and complex history, of having been subject to a variety of historical 'forces' and of being shaped or framed in response to a variety of socio-political concerns and considerations (see, e.g. Williams 1997, pp. 118, O’Connor \& Sheehy 2000, pp. 1-9, Reeves 2013, pp. 15-20). The historical and socio-political context out of which the concept of suicide has emerged is therefore to be understood as a significant factor in influencing how practitioners think about suicide. Indeed, the context from which the concept of suicide has emerged can not only be understood as exerting an enduring influence on how practitioners think about suicide, but also as influencing professional debate and discussion about what interventions and strategies ought to be guiding contemporary practice. As Cutcliffe and Santos (2012) suggest, "how a concept or issue is 'framed' has a huge impact (if not dominant influence) on how that concept is used, discussed and debated in any associated discourse - including a practice discourse" (p. 245). 
It has been suggested, at least since the emergence of modern psychiatry as a discipline, that one of the most common and enduring conceptual understandings of suicide has been to frame it within the context of 'mental illness' or 'mental disorder' (Heyd \& Bloch 2000, p. 447, Cutcliffe \& Santos 2012, p. 246). While there exist a number of explanatory models as to why suicide ought to be understood within this context, the most common explanation proposes that the symptoms of mental illness in particular, 'cognitive distortions', 'irrationality' and 'impulsivity' - are 'an important causal factor' in the person committing suicide and that, without these symptoms being present, the person would not have killed themselves (Mishara \& Chagnon 2011, p. 612). There exists a substantial body of literature that proposes that an understanding of suicide within the context of mental illness is appropriate - with suicidal behaviour being associated with affective disorders, substance-use related disorders, personality disorders and schizophrenia (see, e.g. Cavanagh et al. 2003, Bertolote et al. 2004, Hawton \& van Heeringen 2009, Lönnqvist 2009). However, there also exists a body of literature that contradicts and challenges, on various methodological and conceptual grounds, the automatic association of suicide with mental illness (see, e.g. Shneidman 1996, Tanney 2000, Szasz 2002, van Praag 2004). For example, in highlighting a contentious form of reasoning that entails a conflation of suicide with mental illness, Pilgrim (2010) proposes that the error lies in retrospectively imputing mental disorder and irrationality in all cases where a person has considered, attempted or committed suicide. As he makes clear, "when and if a person commits suicide, then it is easy to argue that the 'balance of their mind' was faulty at the fatal moment or that they had a prior mental disorder, which made them particularly prone to self-sacrifice" (Pilgrim 2010, p. 176). 
It is important to note, however, that questioning the manner in which suicide is framed within the context of mental illness is not to be understood as proposing that the association of suicide with mental illness is invalid. It may be that suicide, some of the time, reflects cognitive distortions, irrationality and impulsivity (Pilgrim 2010, p. 176). Rather, what is being challenged is the automatic association and potential conflation of suicide with mental illness and, in particular, the suggestion that those who express suicidal ideation, attempt to commit suicide or succeed in committing suicide must, by that fact itself, have a mental illness (Cutcliffe \& Santos 2012, p. 246). Moreover, to the extent that suicide is understood within the context of mental illness then this has important implications for what interventions and strategies are considered to be appropriate for those individuals who are judged to be at risk. In so far as suicidal ideation and behaviour is understood as being symptomatic of a mental illness (and, in particular, as being a consequence of irrationality and impulsivity) then it has been suggested that the predominant intervention has traditionally been a pharmacological one supported by the 'custodial and defensive practices' of containment, seclusion, close observations and no-suicide contracts (Henden 2008, Cutcliffe \& Santos 2012, Goldney 2011). Again, to challenge the manner in which suicide is framed within the context of mental illness is not to propose that such defensive practices have no clinical function or value. However, the efficacy of such interventions has repeatedly been called into question with it being suggested that, rather than actually seeking to address 'the problem', such interventions are more concerned with limiting damage resulting from the problem and do little or nothing to address the individual's emotional and psychological needs (Cutcliffe \& Barker 2002, McMyler \& Pryjmachuk 2008, Cutcliffe \& Stevenson 2008). 


\section{Camus and suicide}

It is within this context - the association and potential conflation of suicide with mental illness or disorder, and the therapeutic dominance of pharmacological and custodial interventions for those judged to be at risk - that Camus's account of suicide can be understood. In order to do so, it is productive to begin by noting that Camus (2000a) does not present his discussion of suicide in The Myth of Sisyphus by seeking to identify specific causal factors or events that would lead an individual to contemplate or commit suicide. As he makes clear: 'There are many causes for a suicide and generally the most obvious ones were not the most powerful' (Camus 2000a, p. 12). Such an attempt to retrospectively determine, from a multiplicity of possible events, which specific events or factors led the individual to commit suicide is said to be 'almost always unverifiable' (Camus 2000a, p. 12). Instead, Camus (2000a) proposes that a more productive way to investigate and understand the phenomena of suicide is to 'deduce' what the act itself communicates or 'implies' (p. 13). In doing so, he suggests that those who consider, attempt or commit suicide are making a declaration or, as it were, a 'confession' about life and their relation to it. In particular, the act of suicide "is confessing that life is too much for you or that you do not understand it. Let's not go too far in such analogies, however, but return to everyday words. It is merely confessing that that "is not worth the trouble" (Camus 2000a, p. 13). Therefore, rather than seeking to understand suicide by attempting to determine which events are 'an important causal factor', Camus's work suggests that the individual who has committed suicide has made a declarative judgement about the worth or the value of life, has undergone a 'crisis' in which the value of existence has been questioned and, in reaching the conclusion that it does not possess worth or value, has responded by committing suicide. 
Is it possible, however, to say more about the process that would lead an individual to make such a declarative judgement about the value of life? Is it possible to further elucidate why an individual would reach the conclusion that life has no value and, in response to that conclusion, commit suicide? To address these interconnected questions, it is necessary to elucidate that which Camus (2000a) refers to simply as 'the absurd'. Indeed, he proposes that the focus of his concern in The Myth of Sisyphus is precisely to examine the relation between suicide and the absurd and, in particular, to determine the degree to which suicide is to be understood as a solution to the absurd (Camus 2000a, pp. 13-14). In particular, Camus (2000a) proposes that the absurd is to be understood in terms of a contradictory or frustrated encounter between the profound human desire for life to have a meaning - for life to possess a 'unity', 'great idea' or 'overarching, grand explanation' that serves as a context within which the various struggles and sorrows of an individual's life can make sense (p. 15) - and the realisation that there is no grand explanation or, if there is, it is beyond the achievement of human reason to discern it (p. 51). However, the absurd is not to be found, as it were, 'in man' and neither is it to be found 'in the world', but is instead to be understood as that which arises as a consequence of the 'encounter', 'confrontation' and 'disjunction' between the individual and the world (Camus 2000a, pp. 32-34). In illustrating the manner in which the absurd is to be understood as arising out of a contradictory, disjunctive relation between an individual's desire to discern life's meaning and the apparent meaninglessness of life, Camus (2000a) makes it clear that the absurd 'is that divorce between the mind that desires and the world that disappoints, my nostalgia for unity, this fragmented universe and the contradiction that binds them together' (p. 50). 
Suicide is therefore to be understood by Camus as a confession that life possesses no worth or value, and this judgement arises as a consequence of the absurd, contradictory encounter between the individual's desire to make sense of the struggles and sorrows of life and the apparent lack of an overarching meaning that would enable them to do so. Not every individual, however, will respond to the apparent absurdity of existence by reaching the nihilistic conclusion that life possesses no value or worth. Indeed, driven by what is referred to as the 'nostalgia for unity' or 'appetite for the absolute' that is said to reflect 'the essential impulse for the human drama' (Camus 2000a, p. 23), many will adopt a great idea or grand narrative that satisfies the desire for life to possess a meaning. As Camus (2000a) proposes, there are a variety of grand narratives - religious, philosophical and political (p. 35, p. 189) - that purport to disclose the supra-historical, transcendent and overarching explanation of the world and provide the individual with a context in which to situate the meaning of their own life. However, in accordance with the repeated suggestion that modernity is characterized by a growing incredulity towards such overarching explanations or grand, metanarratives (see, e.g. Nietzsche 1974, p. 279, Lyotard 1997, p. xxiv, Vattimo 1999, p. 28, Deleuze \& Guattari 2000, p. 308, Frankl 2004, p. 111, Roberts 2007, p. 277), Camus's (2000a) work suggests that for many the acceptance of these ostensible explanations will be unacceptable in so far as they necessitate 'the leap' to believe, or maintain faith, in their validity (pp. 42-3). Rather than addressing the absurd, rather than resolving the confrontation between the human desire to discern life's meaning and the apparent meaninglessness of life, Camus (2000a) makes it clear that the leap of faith involved in accepting such supra-historical, overarching explanations of the world is a way to 'escape' the absurd that, for some individuals, demands an unacceptable 'sacrifice of the intellect' (p. 40). 


\section{Camus, suicide and mental illness}

In presenting suicide as a declarative judgement about the value of life that arises as a response to the absurd, Camus's work can be understood as providing a profound challenge to the framing of suicide within the context of mental illness. Against the automatic association and potential conflation of suicide with mental illness, Camus radically reconceptualizes suicide such that it is understood as a terminal point in the attempt to address a profound existential problem; namely, the uniquely human and profoundly challenging endeavour to make sense of the struggles and sorrows of life. In particular, Camus's work suggests that suicide is to be understood as the outcome of a contradictory encounter between an individual's attempt to make sense of life and the inability to discern an overarching explanation that would enable them to do so. In contrast to an understanding of suicide within the context of mental illness and irrationality, Camus's work suggests that the suicidal individual has been unable to take the 'non-rational' or 'irrational' leap of faith involved in accepting the validity of an explanation of the world provided by a grand religious, philosophical or political idea. That is, in seeking to make sense of life and its various challenges, the individual has attempted to do so through the employment of their intellect or reason and - in concluding that existence is absurd, in concluding that life possesses no meaning or, if it does, it is beyond the achievement of the individual's reason to discern it - has pursued that reason to its limits. In characterising this uncompromising adherence to reason, Camus (2000a) proposes that: 'My reasoning wants to be faithful to the evidence that aroused it...There can be no question of masking the evidence, of suppressing the absurd...Any other position implies for the absurd mind deceit and the mind's retreat before what the mind itself has brought to light' (p. 50). 
Moreover, against suggestions to the contrary (O'Dwyer 2012, p. 173), Camus's challenge to the automatic association and potential conflation of suicide with mental illness (and his radical repositioning of suicide within the context of the human, existential endeavour to make sense of life) does not entail that his work is unconcerned with the affective dimensions of suicide. The condition in which consciousness 'awakens' to the absurd, a condition in which the individual, attempting to make sense of life and its struggles, reaches the conclusion that life possesses no meaning that will enable them do so, is said to be characterised by a hopeless weariness, estrangement and dislocation (Camus 2000a, pp. 19-20, Young 2005, p. 163). As Camus (2000a) makes clear: 'A world that can be explained even with bad reasons is a familiar world. But, on the other hand, in a universe suddenly divested of illusions and lights, man feels an alien, a stranger. His exile is without remedy since he is deprived of the memory of a lost home or the hope of a promised land' (p. 13). Therefore, to the extent that suicide is reconceptualized as a response to the absurd - a profoundly distressing condition of estrangement and alienation in which the individual is divested of hope of making sense of life's struggles - Camus's work not only challenges the framing of suicide within the context of mental illness, but it can also be understood as calling into question the sufficiency of the interventions that have traditionally been associated with an understanding of suicide within that context. That is, in challenging an understanding of suicidal ideation and behaviour as being symptomatic of a mental illness - and of cognitive distortions, irrationality and impulsivity in particular - Camus's work also challenges the primacy and predominance that has traditionally been accorded to pharmacological interventions supported by the custodial and defensive practices of containment, seclusion, close observations and no-suicide contracts. 
While a reconceptualization of suicide as a response to the absurd suggests that pharmacological interventions supported by custodial, defensive practices will have limited benefit in assisting an individual who is seeking to make sense of life and its struggles, it does not entail a rejection of the function that those practices may have, for example, in attempting to maintain and secure the physical integrity of an individual judged to be at risk. However, Camus's work does suggest that such practices ought to be complimented by a more proactive, existentialist approach that acknowledges, and is able to meaningfully respond to, the profoundly challenging existential endeavour that the suicidal individual is undertaking (see, e.g. Yalom 1980, Frankl 2004, Roberts 2008, van Deurzen-Smith 2012, Cooper 2012, Langdridge 2013). While a detailed discussion of such an existentialist approach is beyond the bounds of this paper, Camus's work suggests that what is of central importance is facilitating the realisation that, although an individual may be unable to discern or maintain faith in a grand, overarching idea within which to situate life's struggles, this ought not to lead to the conclusion, the specifically nihilistic conclusion, that life is without value and worth. Indeed, he makes it clear that The Myth of Sisyphus is a book which 'declares that even within the limits of nihilism it is possible to find the means to proceed beyond nihilism' (Camus 2000a, p. 7). In particular, his work suggests that even if an individual concludes that there is no overarching meaning that can serve as a context in which to situate, and make sense of, life's various struggles, there exists an opportunity to engage in a collaborative exploration of what those struggles can come to mean in the unique context of that individual's life, an opportunity to creatively respond to life's challenges in a manner that enables the construction of a system of personal meaning that promotes new growth, development and direction in that individual's life. 


\section{Conclusion}

Despite its complex and challenging tenor, it has been suggested that Camus's work, and The Myth of Sisyphus in particular, can be productively employed to provide a radical and significant existentialist reconceptualization of suicide. By doing so, his work can be understood as calling into question the manner in which suicide has been framed within the context of mental illness, and within the context of irrationality in particular, as well as challenging the primacy and predominance given to pharmacological interventions and the custodial practices that are associated with an understanding of suicide within that context. While the literature indicates that pharmacological interventions and custodial practices continue to be the dominant form of mental health care for those individuals judged to be at risk of suicide (see, e.g. Cutcliffe \& Barker 2002, Gilje et al. 2005, Cutcliffe \& Stevenson 2008), there is a growing body of literature that suggests that this is changing. For example, in seeking to call into question traditional conceptualizations, associated attitudes and clinical interventions for those individuals judged to be at risk of suicide, contemporary suicidal behaviour management training programmes place increased emphasis on the 'existential crisis' associated with suicide and the employment of a broadly solution-focused approach to address such crisis (see, e.g. Gask et al. 2008, Henden 2009, Reeves 2013). Therefore, while not dismissing the clinical role that pharmacological interventions supported by custodial, defensive practices may have in responding to the individual judged to be at risk of suicide, Camus's work can be understood as an exhortation for mental health professionals to continue to develop the skills to be able to acknowledge, discuss and meaningfully respond to the profoundly challenging existential aspects of suicide. 


\section{References}

Bertolote J., Fleischmann A., De Leo D. \& Wasserman D. (2004) Psychiatric diagnosis and suicide: revisiting the evidence. Crisis 25, 147-155.

Bronner S.E. (1999) Camus: Portrait of a Moralist. Minnesota Press, Minneapolis.

Camus A. (2000a) The Myth of Sisyphus. Penguin, London.

Camus A. (2000b) The Rebel. Penguin, London.

Camus A. (2000c) The Outsider. Penguin, London.

Camus A. (2000d) The Plague. Penguin, London.

Camus A. (2000e) The Fall. Penguin, London.

Cavanagh J.T.O., Carson A.J., Sharpe M. \& Lawrie S.M. (2003) Psychological autopsy studies of suicide: a systematic review. Psychological Medicine 33, $395-405$.

Cooper M. (2012) Existential Therapies. Sage, London.

Cutcliffe J.R. \& Barker P. (2002) Considering the care of the suicidal client and the case for 'engagement and inspiring hope' or 'observations'. Journal of Psychiatric and Mental Health Nursing 9, 611-621. 
Cutcliffe J. \& Santos J.C. (2012) Suicide and Self-Harm: An Evidence-Informed Approach. Quay Books, London.

Cutcliffe J.R. \& Stevenson C. (2008) Feeling our way in the dark: The psychiatric nursing care of suicidal people - A literature review. International Journal of Nursing Studies 45, 942-953.

Deleuze G. \& Guattari F. (2000) Anti-Oedipus: Capitalism and Schizophrenia. Continuum, London.

Deleuze G. \& Guattari F. (2003) What is Philosophy? Verso, London.

Frankl V.E. (2004) Man's Search for Meaning. Rider, London.

Gask L., Lever-Green G. \& Hays R. (2008) Dissemination and implementation of suicide prevention training in one Scottish region. BMC Health Services Research 8: 246, 1-13

Gilje F., Talseth A.G. \& Norberg A. (2005) Psychiatric nurses' response to suicidal psychiatric inpatients: struggling with self and sufferer. Journal of Psychiatric and Mental Health Nursing 12, 519-526.

Goldney R.D. (2011) Antidepressants and Suicide Prevention. In: International Handbook of Suicide Prevention: Research, Policy and Practice (eds O' 
Connor R., Platt S. \& Gordon J.), pp. 457-471. Wiley-Blackwell, Chichester.

Hawton K., ed. (2005) Prevention and Treatment of Suicidal Behaviour: From Science to Practice. Oxford University Press, Oxford.

Hawton K. \& van Heeringen K. (2009) Suicide. The Lancet 373, 1372-1381.

Henden J. (2009) Preventing Suicide: The Solution Focused Approach. John Wiley \& Sons, Chichester.

Heyd D. \& Bloch S. (2000) The ethics of suicide. In: Psychiatric Ethics (eds Bloch S., Chodoff P, Green S.A.), pp. 441-460. Oxford University Press, Oxford.

Hughes E.J., ed. (2007) The Cambridge Companion to Camus. Cambridge University Press, Cambridge.

Langdridge D. (2013) Existential Counselling and Psychotherapy. Sage, London.

Lönnqvist J. (2009) Major psychiatric disorders in suicide and suicide attempters. In: Oxford Textbook of Suicidology and Suicide Prevention: A Global Perspective (eds Wasserman D. \& Wasserman C.), pp. 275-286. Oxford University Press, Oxford.

Lyotard J.F. (1997) The Postmodern Condition: A Report on Knowledge. Manchester University Press, Manchester. 
McMyler C. \& Pryjmachuk S. (2008) Do 'no-suicide' contracts work? Journal of Psychiatric and Mental Health Nursing 15, 512-522.

Mishara B.L. \& Chagnon F. (2011) Understanding the relationship between mental illness and suicide and the implications for suicide prevention. In: International Handbook of Suicide Prevention: Research, Policy and Practice (eds O’Connor R., Platt S. \& Gordon J.), pp. 609-623. Wiley-Blackwell, Chichester.

Nietzsche F. (1974) The Gay Science. Vintage Books, New York.

O’Connor R. \& Sheehy N. (2000) Understanding Suicidal Behaviour. BPS Books, Leicester.

O’Connor R., Platt S. \& Gordon J., eds (2011) International Handbook of Suicide Prevention: Research, Policy and Practice. Wiley-Blackwell, Chichester.

O’Dwyer K. (2012) Camus's Challenge: The Question of Suicide. Journal of Humanistic Psychology 52, 165-177.

Pilgrim D. (2010) Key Concepts in Mental Health. Sage, London.

Reeves A. (2013) Counselling Suicidal Clients. Sage, London. 
Roberts M. (2007) Modernity, mental illness and the crisis of meaning. Journal of Psychiatric and Mental Health Nursing 14, 277-281.

Roberts M. (2008) Facilitating recovery by making sense of suffering. Journal of Psychiatric and Mental Health Nursing 14, 277-281.

Shneidman E.S. (1996) The Suicidal Mind. Oxford University Press, New York.

Szasz T. (2002) Fatal Freedom: The Ethics and Politics of Suicide. Syracuse University Press, Westport.

Tanney B.L. (2000) Psychiatric diagnoses and suicidal acts. In: Comprehensive Textbook of Suicidology (eds Maris R.W., Berman A.L. \& Silverman M.M.), pp. 311-340. Guilford Press, New York.

van Deurzen-Smith E. (2012) Existential Counselling and Psychotherapy in Practice. Sage, London.

van Praag H.M. (2004) Stress and suicide: are we well equipped to study this issue? Crisis 25, 80-85.

Vattimo G (1999) Belief. Blackwell, Oxford.

West D. (2010) Continental Philosophy. Polity Press, Cambridge. 
Williams M. (1997) Cry of Pain: Understanding Suicide and Self-Harm. Penguin, London.

Yalom I. (1980) Existential Psychotherapy. Basic Books, New York.

Young J. (2005) The Death of God and the Meaning of Life. Routledge, London.

Zaretsky R. (2010) Albert Camus: Elements of a Life. Cornell University Press, Ithaca.

Zaretsky R. (2013) A Life Worth Living: Albert Camus and the Quest for Meaning. The Belknap Press, Cambridge, MA. 